\title{
Exploring the benefit of farming slideshow to agri-business marketing
}

\author{
Yung-Hsing Peng ${ }^{a}$, Po-Cheng Huang, Ying-Hsu Chen, Chia-Cheng Lin and Ming-Hsiang Wang \\ Innovative DigiTech-Enabled Applications and Services Institute, Institute for Information Industry, \\ Taipei 106, Taiwan
}

\begin{abstract}
In Taiwan agriculture, most of the production management is done by paperwork. This kind of approach is labor-costing, and unable to give real-time information, which makes it difficult to disclose sufficient information from production, and therefore results in the problem of food safety. To break the bottleneck, the Institute for Information Industry (III) develops the Smart Agri-management Platform (S.A.M.P.), providing cloud services for agricultural production and sale management. In this paper, we adopt the S.A.M.P. to collect farming records containing images, date, field location, and task name. Traditionally, farming records are used to generate a table of texts for traceability. However, it is difficult to arouse the interest from customers by merely using texts. Therefore, this paper proposes the mechanism of farming slideshow, a new presentation of traceability by dynamic arrangement to farming records on S.A.M.P. The experiment is performed in the Yongling organic farm in Kaohsiung, generating over 30,000 vegetable packages supporting farming slideshow. According to 42 valid questionnaires from customers, $83 \%$ of them express higher willing to buy products with farming slideshow than those with only texts. Therefore, food traceability with slideshow can offer benefit to agri-business marketing, which is a positive reference for future agriculture.
\end{abstract}

\section{Introduction}

In recent years, food safety has become an important social issue in Taiwan, which arouses more and more public attention. Since people beware of what they eat, this market trend definitely influences Taiwan agriculture: the origin of most Taiwanese food. Currently, there are two main certificates for agricultural products, which are the traceable agricultural products (TAP), and the CAS Taiwan organic label. These certificates are issued by certification bodies, such as the Tse-Xin Organic Certification Corporation (TOC), or the National Chung Hsing University. During the certification, the environment of the farmland will be carefully examined, and it is necessary for farmers to regularly provide their farming records, which are usually managed by paperwork. The motivation of such certificate is to show the safety of agricultural products to customers, which promotes the trading of safe products. Taking the TAP as an example, customers can trace the farming records by inputting the unique query code attached on packaged fruits or vegetables. However, to our knowledge, the presentation of such farming records is merely text that contains the date and the name of farming task.

\footnotetext{
${ }^{\text {a }}$ Corresponding author : pengyh@iii.org.tw
} 
For general customers, the name of farming task can be a professional term not easy to comprehend. In addition, the recording habit of farmers deeply affects the reliability of farming data. When records are collected by paperwork, the date and the name of task can be improperly filled, and the recognition of hand-written text also results in some hardness for data process. Because of the above phenomenon, it is difficult to arouse the interest from customers even if the code of traceability is provided. In other words, the present solution for processing farming records can hardly benefit the sale of agri-products. Therefore, it is worth study to develop a service that fulfils both the need of certification and marketing.

Recently, the Institute for Information Industry (III) develops the Smart Agri-management Platform (S.A.M.P.) [0] that provides innovative cloud services for agricultural production and sale management. For agricultural data analysis, many interesting researches have also been investigated, such as the crop growth estimation [2-5], farmland climate tracking [6-8], and crop price prediction [9-11]. There are similar systems developed for agricultural data analysis, such as the Farmlogs[12] and KisanHub[13]. However, the utilization of agricultural data for marketing is scarcely discussed. In this paper, we propose the mechanism of farming slideshow, which is a new presentation of traceability achieved by dynamic arrangement to farming records on S.A.M.P. The organization of this paper is as follows. In Section 2, we describe the methodology for creating farming slideshow. In Section 3, we propose the experimental results in Yongling organic farm. Finally, we give some conclusions and future work in Section 4.

\section{Methodology}

In this section, we first introduce the architecture of production management using S.A.M.P. After that, we briefly describe the implementation for generating the farming slideshow.

\subsection{Architecture}

The architecture of the production management using S.A.M.P. is shown in Figure 1. The S.A.M.P. utilizes front-end apps and back-end web applications for data acquisition and production management, respectively. With S.A.M.P., managers can supervise each field (farmland) with ease, and assign proper tasks to farmers of concerns. Next, farmers can confirm the content of task and report the completion of task with their mobile phone. In this way, the farming data are recorded during the management, which eliminates the paperwork.

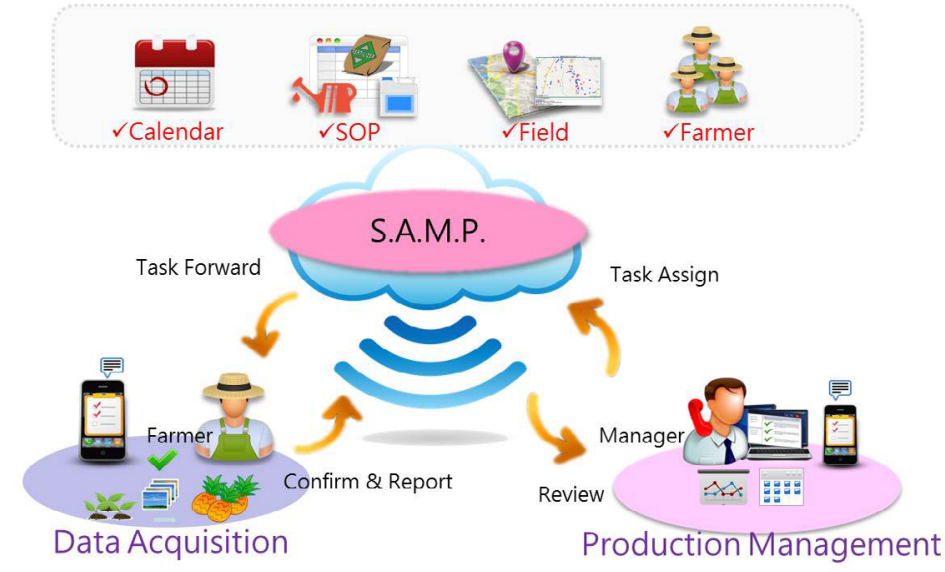

Figure 1. The architecture of the production management using S.A.M.P. 


\subsection{Implementation}

Currently, the server of S.A.M.P. is maintained by the Institute for Information Industry, and the farming slideshow is implemented as an embedded service on S.A.M.P. The material used for generating the slideshow include (1)the name of the agri-enterprise, (2)the location of the production site (field), (3)the period of cultivation, (4)the names and the dates for finished tasks, (5)the name of the farmer who completed the task, and (6)the farming image of the task. The above information can be collected in different stages when managers and farmers are using S.A.M.P. First, the name of the agri-enterprise is retrieved from the user profile. The location of fields can be specified by drawing polygons with our web application, or by referring to the GPS signal returned from mobile phone. The period of cultivation is configured by production managers when they are making the planting schedule. The names of tasks are also defined by the managers when they are establishing the SOP for cultivation. Meanwhile, the dates of finished tasks depend on the time when farmers report their completion of tasks, and the names of farmers can be easily mapped by their login accounts. Finally, the farming images are from the reported pictures that farmers take with their mobile phones. On S.A.M.P., the collected information is first represented in table form. With proper re-organizing, the information can come in the form of slideshow with QR code. The screenshots of our implementation is given as Figure 2.

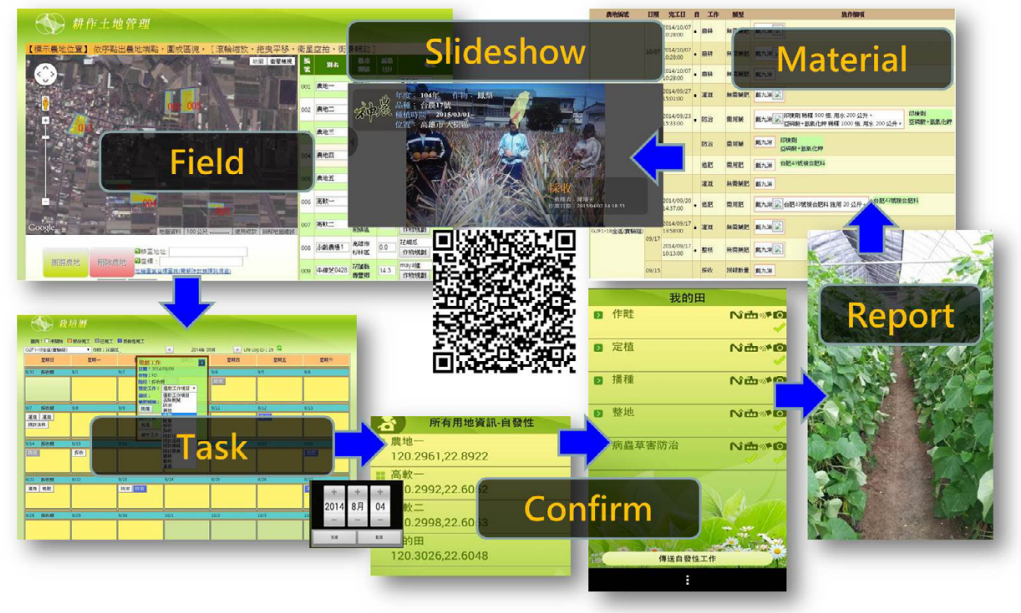

Figure 2. The implementation for the farming slideshow on S.A.M.P.

\section{Experimental Results}

To perform the experiment, we cooperate with the Yongling organic farm in Kaohsiung. The experiment began from October $1^{\text {st }}, 2015$ to December $31^{\text {st }}, 2015$. With the app of S.A.M.P., the staff in Yongling collected farming data via their mobile phones, reporting the dates, names, and images of tasks to the platform. By processing these data, the S.A.M.P. generates 57 farming slideshow for 16 different vegetables planted in 30 greenhouses. On average, each slideshow covers a 28-day cultivation period from seedling to harvest. During the experiment, the produced farming slideshows are further transformed into 30,000 QR codes attached on packed vegetables of weight $250 \mathrm{~g}$. To investigate the effect of farming slideshow for agri-product marketing, Yongling designed a questionnaire for customers who are interested to buy organic vegetables. In total, the questionnaire was given to 55 customers. According to 42 valid returns, farming slideshow offers better understanding of agricultural production to $95 \%$ customers, and $83 \%$ of customers express higher willing to buy products with farming slideshow than those with only text descriptions. The results of questionnaire are given in Table 1. 
Table 1. The questionnaire for exploring the benefit of farming slideshow.

\begin{tabular}{|c|c|c|}
\hline No. & Survey & Statistics \\
\hline 1 & You used to purchase organic agri-products. & $95.3 \%$ \\
\hline 2 & You used to read some QR code with your mobile phone. & $69.8 \%$ \\
\hline 3 & $\begin{array}{l}\text { You prefer to buy agri-products with TAP or CAS labels than those without } \\
\text { any labels. }\end{array}$ & $88.4 \%$ \\
\hline 4 & $\begin{array}{l}\text { You used to buy agri-products that support on-line traceability for farming } \\
\text { records. }\end{array}$ & $60.5 \%$ \\
\hline 5 & $\begin{array}{l}\text { You used to trace the farming records spontaneously. (If your answer is "No", } \\
\text { please go to question No. } 7 .\end{array}$ & $14.0 \%$ \\
\hline 6 & You used to trace farming records with images. & $7.0 \%$ \\
\hline 7 & Farming slideshows provide more messages than text descriptions do. & $86.0 \%$ \\
\hline 8 & $\begin{array}{l}\text { Farming slideshow can effectively disclose the information of production } \\
\text { process. }\end{array}$ & $100.0 \%$ \\
\hline 9 & $\begin{array}{l}\text { The cost for supporting farming slideshow is higher than that for supporting } \\
\text { text descriptions. }\end{array}$ & $74.4 \%$ \\
\hline 10 & $\begin{array}{l}\text { Farming slideshow gives you better understanding for the production of agri- } \\
\text { products than pure text does. }\end{array}$ & $95.3 \%$ \\
\hline 11 & $\begin{array}{l}\text { You are happy to see that farming slideshow will someday replace the } \\
\text { certification with only texts. }\end{array}$ & $100.0 \%$ \\
\hline 12 & Revealing the production process can increase your willing to buy the product. & $90.7 \%$ \\
\hline 13 & Farming slideshow increases your willing to buy agri-product. & $83.7 \%$ \\
\hline 14 & Farming slideshow helps you quickly review the agricultural production. & $87.2 \%$ \\
\hline 15 & Farming slideshow helps you clearly understand the agricultural production. & $88.4 \%$ \\
\hline 16 & $\begin{array}{l}\text { How much extra money (in Taiwanese dollars) are you willing to pay for each } \\
\text { packed vegetable, for obtaining its farming slideshow. }\end{array}$ & 1.48 \\
\hline
\end{tabular}

In Figure 3, we provide some sample labels in Yongling, and readers can watch farming slideshows by scanning the QR codes. Note that for the purpose of publication, the product names in Figure 3 are translated from the original Chinese labels.
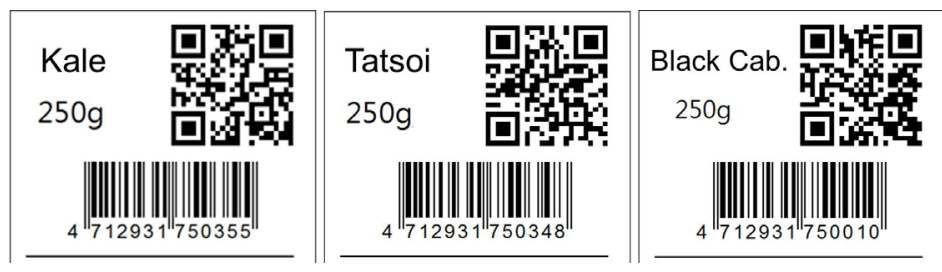

Figure 3. The sample labels produced for the experiment in Yongling organic farm.

\section{Conclusions}

In this paper, we propose the farming slideshow as a service for agri-business marketing. This service is implemented on S.A.M.P., and its benefit is verified by an experiment on Yongling organic farm. From the experimental results, one can see that farming slideshow successfully draws the attention from most customers. In addition to the public attention for information disclosure, Table 1 expresses two interesting phenomenon. First, though farming slideshow seems to take additional efforts, there are only $75 \%$ customers believe that it will increase production cost. That is, about $25 \%$ customers 
notice that the convenience brought by S.A.M.P. can reduce laboring cost on doing paperwork. In addition, customers are willing to pay little extra money for purchasing products with farming slideshow, and all of them are happy to see that farming slideshow will someday replace the text description. Finally, the statistics for question 5 is only 14\%, which implies that farming slideshow is better to be displayed actively on screen, in order to catch the eyes from customers. In summary, the proposed farming slideshow achieves a good initial result on agri-business marketing. In the future, we would like to extend the idea to food processing industry, to make a farm-to-table disclosure of food information.

\section{Acknowledgment}

This study is conducted under the "Online and Offline integrated Smart Commerce Platform (3/4)" of the Institute for Information Industry which is subsidized by the Ministry of Economy Affairs of Taiwan. The authors would like to express their appreciation to the staff of Yongling organic farm for their kind support on farming data collection and questionnaire design for customers.

\section{References}

1. The Smart Agri-management Platform (S.A.M.P., http://shennong.ideas.iii.org.tw/SAMP/)

2. A. Kross, H. McNairn, D. Lapen, M. Sunohara, and C. Champagne, Assessment of rapid eye vegetation indices for estimation of leaf area index and biomass in corn and soybean crops, International Journal of Applied Earth Observation and Geoinformation, 34, 235-248 (2015)

3. Y.H. Peng, C.S. Hsu, and P.C. Huang, Harvest forecasting with environmental information for cucumbers cultivated in net houses, Journal of Advanced Agricultural Technologies, 2, 83-87 (2015)

4. Y.H. Peng, C.S. Hsu, P.C. Huang, and Y.D. Wu, An effective wavelength utilization for spectroscopic analysis on orchid chlorophyll measurement, Proc. of the 2014 IEEE International Conference on Automation Science and Engineering, Taipei, Taiwan, 716-721 (2014)

5. P. Rischbeck, S. Elsayed, B. Mistele, G. Barmeier, K. Heil, and U. Schmidhalter, Data fusion of spectral, thermal and canopy height parameters for improved yield prediction of drought stressed spring barley, European Journal of Agronomy, 78, 44-59 (2016)

6. C.S. Hsu, Y.H. Peng, and P.C. Huang, Climate tracking for farmland using open data from the central weather bureau in Taiwan, Journal of Advances in Information Technology, 6, 227-232 (2015)

7. B. Lalic, M. Francia, J. Eitzinger, Z. Podraščanin, and Ilija Arsenić, Effectiveness of short-term numerical weather prediction in predicting growing degree days and meteorological conditions for apple scab appearance, Meteorological Applications, 23, 50-56 (2016)

8. M. Knapp, Enhanced measurement of weather and climate in natural areas through integrated networks, Transactions of the Kansas Academy of Science, 119, 64-68 (2016)

9. H. Liu and S. Shao, India's tea price analysis based on ARMA model, Modern Economy, 7, 118$123(2016)$

10. Y.H. Peng, C.S. Hsu, and P.C. Huang, Developing crop price forecasting service using open data from Taiwan markets, Proc. of the 2015 Conference on Technologies and Applications of Artificial Intelligence, Tainan, Taiwan, 172-175 (2015)

11. Y.H. Peng, C.S. Hsu, P.C. Huang, An investigation of spacial approaches for crop price forecasting in different Taiwan markets, Proc. of the 2015 Conference on Technologies and Applications of Artificial Intelligence, Tainan, Taiwan, 176-179 (2015)

12. The Farmlogs system (https://farmlogs.com/)

13. The KisanHub system (https://www.kisanhub.com/) 